\title{
Experiências das mulheres na escravidão, pós-abolição e racismo no feminismo em Angela Davis
}

Mulheres, raça e classe.

DAVIS, Angela.

Tradução de Heci Regina Candiani. São Paulo: Boitempo, 2016, 244p.

Em Mulheres, raça e classe, Angela Davis, filósofa estadunidense, negra, feminista, ativista radical dos anos 1970, trouxe grande contribuição para repensar as relações raciais, ressignificar o feminismo e, de forma particular, para o feminismo negro, sobretudo, colocando à tona o racismo no feminismo. Dentre suas experiências, a autora integrou-se ao grupo Panteras negras e o partido Comunista dos Estados Unidos. Foi presa na década de 1970 e candidata à vice-presidência da República em 1980 e 1984.

Nesse livro, Davis pensa a dinâmica da exclusão capitalista tomando como nexo prioritário o racismo e o sexismo, partindo da vivência das mulheres no trabalho escravo, compreendendo o modo de funcionamento das sociedades marcadas pela tragédia da escravidão. Dividido em 13 capítulos ao longo de 244 páginas, reúne estudos de diversas/ os autoras/es, publicações de jornais, cartas e outros documentos, além de depoimentos das/os próprias/os ex-escravizadas/os e descendentes, sobre o ocorrido durante e após a escravidão nos EUA, detectando o racismo explícito e as atrocidades praticadas. Além disso, a autora não descarta testemunhos de homens e de mulheres (brancos/as) falando do lugar de proprietários/as dos/as ex-escravizadas/os.

Os estudos sobre escravidão não visibilizavam as mulheres, camuflando muitas realidades, desde a onda de publicações dedicadas aos estudos sobre a escravidão, nos anos de 1970, que não incluía a situação das mulheres escravizadas, exceto os estudos de Hebert Gutman (1976) a partir da discussão sobre a família negra. A violência contra os/as negros/as na escravidão e pós-abolição tem sido amenizada na literatura modernohegemônica-branca, questão que impulsionou Davis a realizar esse estudo, no qual se acerca desde o século XVII, correlacionando os 300 anos de escravidão, e reporta-se também ao século XX, quando alavancaram os movimentos feministas.

Ao investigar a escravidão nos Estados Unidos, a autora mostra a experiência das mulheres negras diante da desumanização, e aponta o enfrentamento dessa categoria de 
mulher durante e após-abolição, trazendo à tona o significado da experiência das mulheres negras no trabalho escravo para o feminismo e visibilizando as condições similares no pósabolição, abordando a divisão racial e sexual, racismo e sexismo. De um lado, a obra faz refletir que a abolição não significou, de fato, o fim da escravidão e, de outro, mostra a mulher negra como a primeira categoria de mulher no trabalho fora de casa.

Dentre as diversas contribuições, esse trabalho influencia na desconstrução do mito da mulher e do homem negros na perspectiva do corpo/sexo, sexualidade, marcados/as de estereótipos negativos, muitas vezes taxados/as de infratores/as quando vítimas, portanto, sem vozes, subalternizados/as e assujeitados/as. Por essa perspectiva é que as imagens do homem e da mulher são percebidas: "[...] A imagem da mulher negra como cronicamente promíscua. Uma vez aceita a noção de que os homens negros trazem em si compulsões sexuais irresistíveis e animalescas, toda a raça é investida de bestialidade" (Angela DAVIS, 2016, p. 186).

Com a imagem fictícia do homem negro estuprador, ocorrem falsos testemunhos de mulheres brancas se dizendo atacadas, levando-os à condenação (DAVIS, 2016, p. 194, 199 e 200) e, inversamente, a imagem da mulher negra justifica o estupro dos homens brancos a elas, durante e após a abolição, sendo tais homens, "vítimas" da sedução do corpo negro. Por conseguinte, discursos verdadeiros tornaram-se ciência, inscrito na literatura e na "obra de arte" da teoria do racismo científico.

Dessa maneira, na primeira parte do livro Angela Davis mostra múltiplas violências: estupros - como prática desvinculada de instinto sexual dos homens brancos, porém, como parte do conjunto de estratégias para a manutenção do regime escravocrata -, violência como prática dos proprietários da população negra escravizada, a fim de lucros. Cada filho/a nascido/a equivalia uma mercadoria das famílias brancas, mais lucro, cuja mãenegra nem ao menos tinha o direito de experimentar ser genitora.

Com o crescimento do capitalismo (questão que forçou a abolição) no pós-abolição, cria-se uma política de imigração para a mão-de-obra assalariada, não incluindo a população negra, o que gerou a institucionalização da desigualdade racial na estrutura política de vários países, inclusive no Brasil. Essa questão é vista, conforme nota-se em Kabengele Munanga (2006) por meio de mecanismos legislativos, como as políticas segregacionistas, nos genocídios e na tentativa de extermínio da população negra, naturalizando tais práticas.

No trabalho escravo as mulheres negras experimentaram a igualdade com os homens, na produção, na força, nas surras, muitas das quais seguidas de morte, predominando múltiplas violências às mulheres, pelo sexo, estupro, reprodução e lactação. Contudo, esse estudo aponta algo que se opõe a diversos trabalhos sobre a temática - a insubmissão dos/as escravizados/as, durante e na pós-abolição, e aponta como marco o movimento antiescravagista, o qual originou o feminismo negro, apesar da inclusão de mulheres brancas nestes movimentos (DAVIS, 2016, p. 47). Por não terem experiências, as feministas brancas, no século XIX (por volta de 1840), aderiram ao movimento antiescravagista feminino (com a fundação, em 1833, da Sociedade Antiescravagista Feminina da Filadélfia), apresentando outros objetivos em suas pautas: a igualdade com os homens/brancos; porém, tal adesão deu visibilidade ao feminismo, motivo pelo qual é considerado o marco feminista nos Estados Unidos. Nessas diferenças de objetivos no interior da categoria mulher, as causas das mulheres negras ficaram subsumidas, enfraquecendo o feminismo negro, até o alcance dos desígnios das brancas.

Entretanto, compreende-se que, o feminismo negro reinsurge ressignificado nos idos dos anos 1980, aliando militância e academia. Nesse contexto ganha força ao introduzir a questão da interseccionalidade - termo conceituado especialmente por Kimberlé Crenshaw 
(2002), de modo a pensar a experiência das mulheres negras como forma de reorganizar o feminismo diante do gênero, da raça, da classe, agregando outros marcadores sociais, como sexualidade, geração, religião e territorialidade.

No quarto capítulo destaca-se o racismo no movimento sufragista, evidenciando os obstáculos e submissão no interior da categoria mulher. Na lista dos opressores, Davis inclui, como instituição racista e omissa, as organizações de direitos das mulheres (fundadas nesse interim) que nada faziam pela população negra, ainda limitada pelas amarras do pós-Abolição, pois sequer incluíam as mulheres negras em suas organizações ou acatavam as denúncias da opressão destas. Muitos são os relatos de que as brancas boicotavam as negras e, as de classe média, não se importavam com a classe trabalhadora branca. Esse cenário resultou nas reinvindicações das mulheres vetadas, além das divisões de grupos (DAVIS, 2016, p. 64-65).

A autora aponta neste estudo os muitos encontros e convenções para os direitos de todas as mulheres (DAVIS, 2016, p. 61-63), mas prevaleciam os direitos para as mulheres brancas, requerendo principalmente o voto, com a proposta do sufrágio, sendo derrotadas na primeira Convenção (a de Seneca Falls, em 1848). Nesta, ficou evidente a ausência das mulheres negras (DAVIS, 2016, p. 67-68) devido, em nosso entendimento, ao racismo e supremacia racial branca. Apesar disso, a autora reconhece muitas contribuições das feministas brancas, como, por exemplo, a tentativa de incluir pessoas negras na educação, até mesmo de criar escolas exclusivas para a raça e universidade para formar professoras negras, cujas ações foram corriqueiramente combatidas. Do outro lado, há descrições de alianças de feministas brancas à estrutura racista, em defesa irrefutável pela supremacia e superioridade de sua raça e dos racismos.

No que se pode considerar como segunda parte da obra, refletindo sobre o significado da emancipação para as mulheres negras, consta que a escravidão e o racismo continuam fortes no pós-abolição. No trabalho, para ambos os sexos, a exclusão, e particularmente às mulheres, ficaram restritas aos serviços domésticos das casas dos brancos e nos serviços pesados nas lavouras, seguindo a violência e estupros no trabalho, com a conivência das mulheres brancas (DAVIS, 2016, p. 97-99).

Davis aponta as conquistas das mulheres, de maneira determinante para as mulheres brancas, com o direito ao voto, resultando no movimento associativo e na separação racial. A filósofa segue na discussão do capitalismo com as mulheres no trabalho submisso, descrevendo sobre as experiências das principais mulheres feministas comunistas, com a influência do Manifesto Comunista, publicado em 1848, por Karl Marx e Friedrich Engels.

É revelada a influência das mulheres negras nos avanços de gênero e na organização do feminismo, que, de forma significativa, mudou a história das mulheres brancas, destacando a grande e relevante contribuição da ex-escravizada e analfabeta Sojourner Truth, em 1851, quando em discurso público proferido em uma convenção de mulheres e, sendo a única mulher negra presente, inquire: "não sou eu uma mulher?" (DAVIS, 2016, p. 70-72). Assim, revela, por meio da experiência do próprio corpo, pois a escravidão apontou no corpo a igualdade física das mulheres negras com a dos homens negros, mostrando que as diferenças entre os sexos, em geral, são construções. Além de que, não é o fato de trabalhar fora que desonra a mulher. No fim, vitória das brancas, diante de alguns objetivos propostos! (Apesar de o direito ao voto só ocorrer no século XX).

Nesse contexto, esta obra revela ódio e preconceito da população branca contra a negra construída na escravidão e legado desta. Dentre as violências organizadas, destacam-se o linchamento e as organizações que visavam o fim desta população, como a KU KLUX KLAN - organização norte-americana conhecida por realizar atos violentos contra a população negra. Dentre suas ações estava: atacar negros/as nas ruas, violentar, matar; 
invadir moradias de pessoas negras e estuprar e matar pessoas do sexo feminino, bem como espancamento e homicídio do sexo oposto, ação que perdurou por longos 80 anos (DAVIS, 2016, p. 189 e 197).

Em uma passagem, é possível ter noção da inescrupulosa educação, cultura e formação das mentalidades da população branca da época, dada desde a infância, além de perceber a conivência das mulheres brancas nas práticas violentas, como os linchamentos aos/às negros/as. Vejamos: "Quando White viajou à Flórida para investigar um linchamento, uma menina de nove ou dez anos contou a ele sobre como nos divertimos queimando os pretos" (DAVIS, 2016, p. 197). Mulheres brancas, inclusive feministas, estavam entre as multidões que assistiam aos linchamentos que ocorriam, muitas vezes, em público - com números apontados em 10 mil assassinatos, entre os anos 1865-1895 (DAVIS, 2016, p. 188) e, no entanto, elas, as feministas, igualmente entendiam ser prática normal. Somente no século XX nota-se, finalmente, o empenho de renomadas mulheres feministas brancas na adesão à luta racial, pelo fim do linchamento, pela campanha antiestupro, ambas as ações perpetradas por organizações terroristas.

Compreende-se que Mulheres, raça e classe ratifica a desmistificação da escravidão como um processo temporário que teve o seu fim com a lei da abolição. Ao contrário, a autora evidencia que este episódio se constituiu como a maior e duradoura violência ocorrida na história do planeta, durante e pós-abolição. Trata sobre a força do racismo, o legado da escravidão, o surgimento do controle da natalidade (defendida pelas feministas), sendo perspectivas de liberdade para as brancas e violência para as negras com as práticas das esterilizações forçadas.

Dentre as suas contribuições, Angela Davis alia academia e militância e intersecciona feminismo, antirracismo e luta de classes, refletindo sobre sexismo, racismo e poder. Ao inserir as categorias gênero, raça e classe, evidencia a interseccionalidade neste estudo, por isso, sugerimos pensar nesta obra como influenciadora para a questão da criação do conceito de interseccionalidade e as abordagens correlatas que se seguiram.

Em outras palavras, esta produção apresenta-se relevante para a atualidade, em vista de que o racismo segue fortemente na sociedade, apesar de mudar de forma considerando os diferentes territórios. Sem desconsiderar o papel do colonialismo e do patriarcado no fenômeno do racismo e do sexismo, esse estudo também contribui para pensar na naturalização das diferenças de papéis no trabalho entre os sexos, como efeito das normas de gênero, e entre as raças, como efeito das hierarquias raciais pautando-se sobre inferioridade versus superioridade humana no contexto da escravidão e concretizada na ciência, sob a literatura-hegemônico-branca racista e androcêntrica fomentada com a teoria do racismo científico. Tendo as desigualdades sexuais como fruto do sexismo, e vendo o racismo no interior do gênero, parece-nos oportuno entender as desigualdades sociais entre as raças, determinantes pelo racismo e sob os efeitos da escravidão. Nesse sentido, vale repensar a classe como um dos fatores, e não como primazia das desigualdades sociais.

\section{Referências}

CRENSHAW, Kimberlé. "Documento para o encontro de especialistas em aspectos da discriminação racial relativos ao gênero". Estudos Feministas, v. 10, n. 1, p. 171-188, 2002.

DAVIS, Angela. Mulheres, raça e classe. Tradução de Heci Regina Candiani. São Paulo: Boitempo, 2016.

MUNANGA, Kabengele. Rediscutindo a mestiçagem no Brasil: identidade nacional versus identidade negra. 2.ed. Belo Horizonte: Autêntica, 2006. 
[Recebida em 25/06/2017 e aprovada em 30/09/2017]

Ineildes Calheiro dos Santos Universidade Federal da Bahia, Salvador, BA, Brasil

Ineildes Calheiro dos Santos (ildafrica@yahoo.com.br) é graduada em Educação Física (UNIME - Lauro de Freitas/BA), Mestra em Crítica Cultural pela Universidade do Estado da Bahia - UNEB e doutoranda em Difusão do Conhecimento. Pesquisa sobre gênero e raça no esporte como mercado de trabalho, com o foco no mundo futebolístico. No mestrado pesquisou sobre árbitras de futebol profissional e no doutorado ampliou para as funções de liderança, observando as diferenças de papéis no esporte, focando o racismo e o sexismo. Nesse sentido, os estudos das relações raciais, focalizando o gênero, e do feminismo, têm sido elementos de meus estudos, na área interdisciplinar, educação e cultura.

Eduardo David Oliveira (afroduda@gmail.com) é pós-doutorando, filósofo e antropólogo. Doutor em Filosofia, professor Adjunto da FACED - UFBA (Faculdade de Educação da Universidade Federal da Bahia) e do Doutorado Multi-institucional e Multidisciplinar em Difusão do Conhecimento - DMMDC (Doutorado em rede locado na UFBA). Ex-coordenador deste citado Programa. Autor de alguns livros e publicações diversas. Pesquisa sobre relações raciais, africanidades e religião africana, incluindo, atualmente, a filosofia andina. 